\title{
Experiência Sintoma Fresta no documentário “Les Glaneurs et la Glaneuse", de Agnès Varda
}

Experiencia Síntoma Grieta, en el documental "Les Glaneurs et la Glaneuse", de Agnès Varda

Experience Symptom Crack, in the documentary "Les Glaneurs et la Glaneuse", by Agnès Varda

\section{Regina Lara Silveira Mello}

PPG em Educação, Arte e História da Cultura Universidade Presbiteriana Mackenzie, São Paulo, Brasil, reginalara.arte@gmail.com 


\title{
Resumo
}

Neste filme a cineasta belga Agnès Varda percorre regiões de produção agrícola da França mostrando pessoas que colhem manualmente as batatas que sobram no campo após a colheita por máquinas da agroindústria e retorna a Paris, onde catadores colhem os restos das feiras livres da cidade. Trata-se de um documentário premiado, 2000, que exala o frescor da descoberta dos fatos pela sensação de espontaneidade no processo de criação, gerando, no entanto, profundas reflexões ao fruidor.

Palavras-Chave: Documentário. Catadores. Experiência. Sintoma.Fresta.

\section{Resumen}

En esta película, la cineasta belga Agnès Varda recorre regiones de producción agrícola en Francia mostrando a personas que cosechan manualmente las patatas sobrantes en el campo después de cosecharlas con máquinas agroindustriales y regresa a París, donde los recicladores cosechan los restos de los mercados libres de la ciudad. Se trata de un documental premiado, 2000, que rezuma la frescura del descubrimiento de hechos debido a la sensación de espontaneidad en el proceso creativo, generando, no obstante, profundas reflexiones en el espectador.

Palavras-Clave: Documental. Respigadores. Experiencia. Síntoma.Grieta.

\begin{abstract}
In this film, the Belgian filmmaker Agnès Varda travels through regions of agricultural production in France showing people who manually harvest the leftover potatoes in the field after harvesting by agribusiness machines and returns to Paris, where waste pickers harvest the remains of the city's free markets. It is an award-winning documentary, 2000, which exudes the freshness of the discovery of facts due to the sense of spontaneity in the creative process, generating, however, profound reflections to the viewer.
\end{abstract}

Keywords: Documentary. Collectors. Experience. Symptom. Crack. 


\section{RESENHA DO DOCUMENTÁRIO "LES GLANEURS E LA GLANEUSE", TRADUZIDO NO BRASIL COMO "OS CATADORES E EU" DE AGNÈs VARDA}

\footnotetext{
A

- assistir o filme "Les Glaneurs et la Glaneuse" as palavras Experiência, Sintoma e Fresta, expressas no tema convite à 10a edição da Revista ARA FAU USP, se apresentavam a todo momento durante a "projeção". A sessão "Doc \& Vinho" foi promovida pela pesquisadora Sarah Yakhni, que se debruça há anos sobre a obra de Agnès Varda, e convidou ao debate a pesquisadora Suzana Oliveira Dias, também sensível e apaixonada pela obra da cineasta. Assistimos isolados, com antecedência, e brindamos ao encontro para debate por vídeo-conferência, cada um com sua taça de vinho em sua própria casa, como fez-se hábito necessário nestes tempos de pandemia e isolamento.
}

As reflexões aqui apresentadas são fruto deste impacto, da percepção desta obra incrível vista à luz dos conceitos que as palavras Experiência Sintoma Fresta, pensadas em tom de paridade, podem sugerir. O filme obteve grande repercussão, 
foi premiado em muitos festivais ${ }^{1}$ e oferece amplas possibilidades de pesquisa e reflexão em diversos temas, como questões de gênero, memória, psicanálise, envelhecimento, meio ambiente, reciclagem, globalização, além da linguagem cinematográfica, especialmente criativa neste documentário pouco menor que um longa metragem, com 82 minutos. Recomendamos, vale muito a pena buscar na internet em plataformas que o disponibilizam como a VIMEO e YouTube ${ }^{2}$.

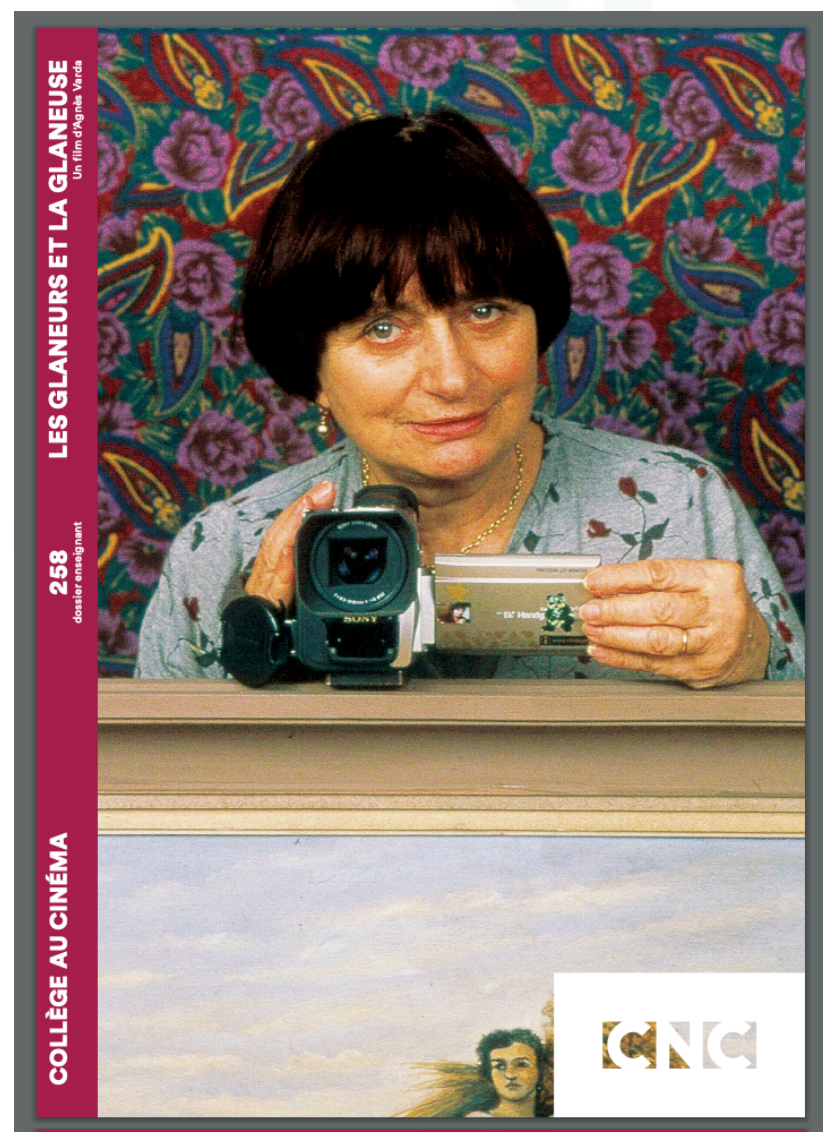

Agnès Varda na capa da revista do Centre National du Cinéma et de l'image animée. Dossier enseignant n. 258.2019.

\footnotetext{
${ }^{1}$ O filme recebeu os seguintes prêmios: Seleção oficial no Festival de Cannes 2000, Prêmio Méliès de Melhor Filme Francês 2000, Prêmio da Academia Europeia de Melhor Documentário 2000, Prêmio do Público no Festival de Montreal 2000, Hugo de Ouro do Festival de Chicago 2000, Melhor Filme pelo Sindicato de Críticos Franceses 2001, Prêmio de Melhor Filme de Não Ficção do Sindicato de Críticos de Los Angeles e do Círculo de Críticos de Nova York 2001, Melhor Filme no Festival de Praga 2001. (Yakhni, 2011)

${ }^{2} \mathrm{Na}$ ocasião em que assisti, as organizadoras do debate nos facilitaram enviando um link, porém ao ser publicada esta resenha o link certamente terá mudado, exigindo nova pesquisa.
} 
Numa descrição rápida do roteiro, trata-se de uma viagem da cineasta Agnès Vardá pelo interior da França, percorrendo as regiões de produção agrícola, passando pelas batatas, um alimento básico muito simbólico na cultura francesa e belga, além do trigo, milho, maçãs, uvas, até retornar a Paris, onde mostra os catadores recolhendo do chão os alimentos perecíveis que não foram vendidos na feira livre, a chamada xepa no Brasil. A equipe vai de carro pelas rodovias entrando em pequenos vilarejos, parando para conversar com agricultores, produtores, donos de plantações e respigadores, pessoas que recolhem os restos das plantações após a colheita mecânica realizada pelas máquinas da agroindústria, num paralelo com a xepa da cidade, no campo ela seria a recolha das sobras das plantações.

Assistindo ao filme percebemos que a tradução do título em português, "Os catadores e eu", não define bem o significado de "Les Glaneurs et la Glaneuse", ficando a meio do caminho. No Brasil associamos normalmente a palavra catador às pessoas que circulam nas cidades recolhendo lixo para reciclar, vendendo em cooperativas ou para uso próprio. O mais correto seria traduzir "glaneur" como respigador, aquele que respiga, que recolhe as espigas que sobram nos campos e reutiliza ${ }^{3}$. Porém pouco se conhece por aqui desta palavra, que também pode ter o sentido de segunda colheita, uma seleção como a própria cineasta sugere ao surgir em cena no seu apartamento em Paris, abrindo uma pequena valise com recordações de uma viagem que fizera ao Japão, manuseando e comentando uma a uma, como legendas faladas do seu museu íntimo, ao relembrar o significado particular de cada objeto recolhido. Neste momento Varda se qualifica como respigadora, se igualando aos respigadores em atitude; mas o uso do pronome eu no título, "Os Catadores e Eu" retira a cineasta deste grupo e a torna distante do ato de respigar. O mais próximo seria "Os Respigadores e a Respigadora", como foi feito na tradução portuguesa do título, mas soaria muito estranho entre nós. Outra solução

\footnotetext{
${ }^{3}$ Res-pi-gar (re- + espiga + -ar) verbo transitivo e intransitivo

1. Apanhar as espigas que ficaram por colher nas searas.

2. [Figurado] Apanhar aquém e além (ex.: respigar provérbios). = COLIGIR, COMPILAR

"respigar", in Dicionário Priberam da Língua Portuguesa [em linha], 2008-2020, https://dicionario.priberam.org/respigar
} 
possível para tradução o título no Brasil seria "Os Catadores e a Catadora", ainda assim a diferença entre respigadores e catadores transparece ao longo do filme, revelando significados bem diversos.

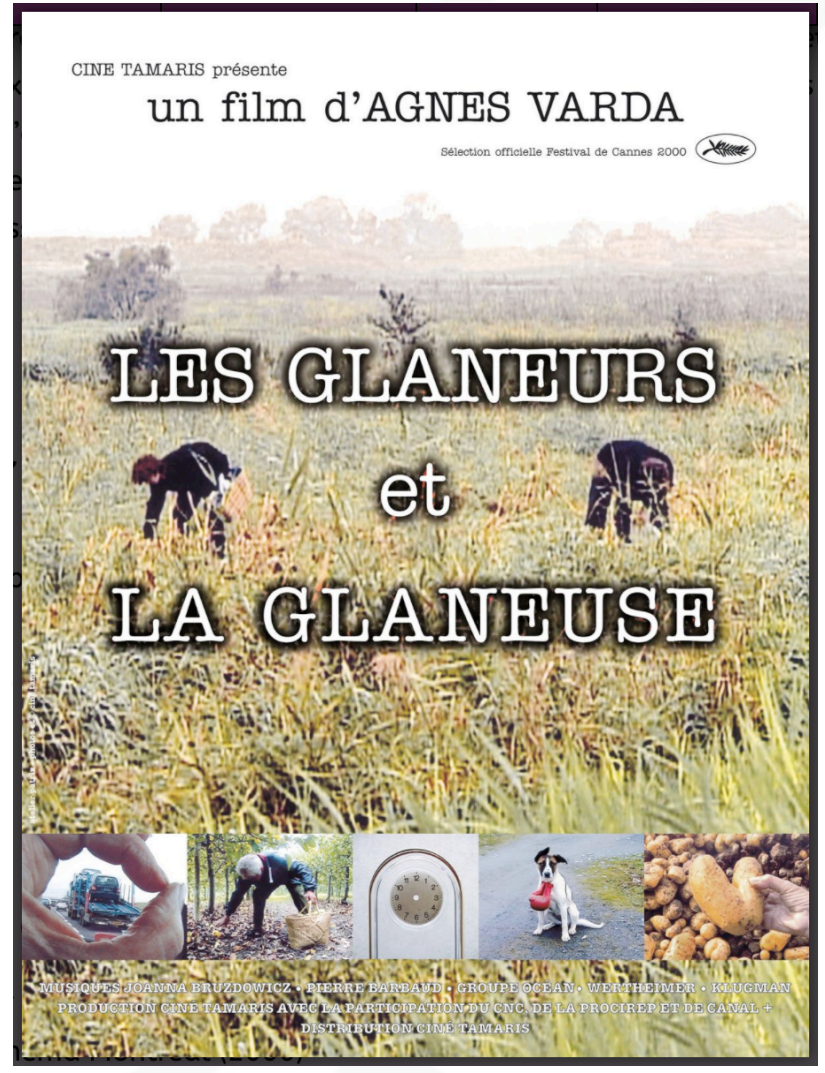

Capa do DVD do filme "Les Glaneurs et la Glaneuse", de Agnès Varda. Distribuição Cine Tamaris, 2000.

\section{EXPERIÊNCIA}

O processo criativo de Agnès Varda não parece corresponder a um roteiro pré determinado, com cenas previstas para lugares específicos. Certamente há uma organização na produção e a equipe parece atuar em conjunto, surgindo ora na frente, ora atrás das câmeras em constante discussão com a diretora. Mas a sensação de improviso permanece e parece expandir o tempo, como se nos remetesse a travessia do desconhecido, numa viagem sem ponto ou momento de parada definidos, com a única certeza de que seremos surpreendidos. Experiência, 
em alemão Erfahrung (erf-fahrung, s.f.), do verbo fahren, significa viajar, atravessar, dirigir, e do latim experientia, tentativa, prova, ensaio (Porto, 1978). A palavra experiência traz incorporada a ideia de alargar a nossa condição no mundo, pela tentativa e erro, sugerindo o tatear, viver e refletir sobre o vivido." Como antes aludi no texto de chamada para este número da revista ARA FAU USP.

A viagem segue pelo olhar da cineasta, somos conduzidos e andamos juntos pelas estradas da França nestas regiões rurais, às vezes seguindo ou ultrapassando grandes caminhões que carregam e distribuem a produção agrícola. A cineasta viaja sentada no banco do passageiro da frente, no que nos parece um pequeno carro, vai fazendo um gesto com as mãos que sugere o possível enquadramento dos caminhões pela câmera; nos ocorre fantasiar que segura um astrolábio, aquele instrumento antigo que os navegadores usavam para traçar a rota pelos mares no período das grandes navegações.

Em determinado momento no meio do filme, Varda está filmando com sua pequena câmera enquanto caminha num campo; aparentemente termina a filmagem e solta a câmera pendurada em seu pescoço, que continua ligada filmando o chão enquanto a tampa da lente balança, por um bom tempo. Nós somos os olhos da cineasta, vemos através da lente e percebemos este esquecimento por tempo suficiente para transformar este objeto, a tampa da lente, em narrador, quase um personagem autônomo. Naquele momento um objeto corriqueiro, reconhecível pelas pessoas que têm o costume de fotografar, assumiu a condução da história, caminhamos juntos até ela se dar conta do esquecimento. Este trecho poderia ter sido retirado na edição do documentário, mas foi mantido ao som de jazz, como metáfora do trabalho conjunto olho humano/lente, feito também de aproveitamentos do acaso, do acolhimento de imprevistos que nos trazem a realidade de volta, para o chão filmado enquanto caminhado. Deparar-se com o acaso é inerente ao experimentar, percebido como algo que não controlamos. 


\section{SINTOMA}

Como ponto de partida da viagem, inspiração, ou motivação inicial, logo no início é mostrada uma página no dicionário em que a palavra "glaneur" aparece ilustrada pelo famoso quadro de Jean-François Millet (1814-1875), “Le glaneuses"(1857), que se encontra atualmente no Museé d'Orsay em Paris ${ }^{4}$. Ali aparecem três mulheres camponesas num imenso campo de trigo mostradas nas três fases da respiga: a primeira, da esquerda para a direita, procura as sobras, a segunda às recolhe e a terceira parece amarrar $\circ$ feixe. Esta sugestão de movimento das glaneuses/catadoras aproxima-se da narrativa cinematográfica, pois há uma ação demonstrada no quadro, e este é reciprocamente mostrado no filme, permitindo uma citação anacrônica, entre duas obras artísticas em tempos diferentes. O gestual, de reclinar o corpo para realizar a colheita é repetido durante todo o documentário, iniciando com a primeira catadora de batatas entrevistada, filmada exatamente nesta mesma posição das catadoras do quadro, e repetida na cidade com os catadores das feiras livres.

O sintoma na história da arte, segundo Georges Didi-Huberman (2013) representa as marcas da sobrevivência da imagem, que retorna sempre como um fantasma em épocas distintas, percorrendo o tempo como memória fluida, indicando repetições dos páthos vistos e percebidos de maneira distinta, conforme mudam os olhares e a realidade. As formas cristalizadas na obra de arte refletem o tempo vivido, corporificado, relacionado a tensões sociais de determinado momento, que retornam constituindo linguagem a ser compreendida pelos sintomas, indícios estéticos oferecidos à fruição ou à crítica.

É interessante notar as origens das reflexões do autor, que o ajudaram a configurar o conceito de sintoma, se afirmam em grande medida no gestual, apontado em diferentes obras como indício de sobrevivência da imagem. Ao analisar o tempo dos

\footnotetext{
${ }^{4}$ MILLET, Jean-François. Le Glaneuses. https://www.musee-orsay.fr/fr/evenements/expositions/auxmusees/presentation-generale.html?zoom=1\&tx_damzoom_pi1\%5BshowUid\%5D=2110\&cHash=8ac69a292b. Acesso em 10 set. 20.
} 
fantasmas segundo Aby Warburg, Didi-Huberman descreve os primeiros estudos do médico e cientista francês Jean-Martin Charcot (1825-1893) sobre a histeria em mulheres, que apontava como um dos sintomas da doença as contorções corporais ou movimentos ilógicos, segundo o padrão sugerido por esculturas da antiguidade grega. Charcot influenciou diretamente o pensamento de Sigmund Freud (18561939), que o contestou na elaboração de suas teorias, mas estas observações do gestual certamente contribuíram a compreensão da subjetividade do sintoma.

O sintoma na medicina refere-se à informação que o paciente oferece ao médico para o diagnóstico da doença, seja descrita verbalmente, expressa corporalmente, tudo o que deva ser entendido como indício, sinal ou traço. Por extensão, ao resgatar o gesto de reclinar o corpo a frente para catar batatas no campo, ou restos de alimentos nas feiras da cidade, repetido tantas vezes no filme por mulheres e homens, Varda o inscreve também como um sintoma da sociedade doente, que mantém uma multidão invisibilizada a espreita, fora do sistema de produção e consumo, sobrevivendo das sobras.

\section{BASEADO EM FATOS REAIS}

Parece incompatível a recriação de fatos num documentário, que a princípio revela sempre a verdade nua e crua, sem montagens ou artifícios que retirem a credibilidade da cena. Mas com Agnès Varda isto é possível sem que duvidemos, por um segundo, da verdade dos fatos. Ao passarem por uma plantação de maçãs é mostrada uma cena em que a cineasta fala sozinha enquanto colhe e come frutinhas sob uma árvore, ruminando o fato de que numa colheita de 3 hectares de maçã, 10 toneladas ainda ficam por apanhar; e naquela plantação onde estavam, o proprietário proibiu a ação dos glaneurs, sem motivo aparente.

Caminhando na sequência por uma plantação de milho, ela encontra um juiz de direito, trajado como tal, com livros abertos nas mãos e faz uma consulta, numa posição de respeito como quem consulta um oráculo: os catadores tem direitos legais? - Sim, responde o juiz! Na França, desde o século XIV o catador que entrar numa propriedade particular após a colheita para praticar a respiga, seja por 
necessidade ou por prazer, não será preso, pois é seu direito legal re-colher o alimento. Muitos proprietários rurais permitem a respiga, incorporada como algo bom para a limpeza do terreno, para evitar acúmulos e desperdícios; a figura do catador não é vista como pedinte ou mendicante, é uma atividade social regular. 0 juiz aparece ali evidentemente fora do seu espaço real de trabalho, no meio da plantação, agindo como um espantalho as avessas que defende o direito do catador dos urubus proprietários de terras que não permitem sua atividade. Quando a equipe retorna a Paris para conversar com os catadores urbanos, uma juíza também aparece no fim de feira, formalmente trajada, para reafirmar que ali também os direitos do catador são garantidos por lei, e além de alimentos re-colhidos, retirar móveis e objetos de dentro de contêineres de lixo na rua também é uma atividade legalmente protegida na França.

Em certo momento do filme a cineasta vai ao Museu de Beaux Arts d'Arras, e mostra uma obra de Jules Breton(1827-1906) em que uma catadora aparece com um feixe de trigo recém colhido sobre os ombros, numa posição altiva, orgulhosa, fitando o observador. Varda se coloca na frente do quadro sobre um banquinho (a cineasta é de estatura bem pequena), na mesma posição com o feixe de trigo nos ombros e fitando o observador; neste momento os funcionários do museu estendem um lençol entre a cineasta e o quadro e é feita uma foto, em seguida ela deixa cair o feixe de trigo e aparece segurando uma câmera filmadora: uma cena especialmente montada para dizer que o ofício da catadora de trigo é agora o ofício da catadora de imagens.

\section{FRESTA}

Chegando a Paris a cineasta percorre feiras nos arredores de algumas grandes estações de metrô, vendo e conversando com os que catam nas ruas, que pegam alimentos crus, pacotes abertos, vez ou outra algo mais interessante e guardam em suas sacolas, como se fizessem compras sem dinheiro. Até chegar a um homem franzino, aparentando uns 40 anos, que pega diretamente do chão e come imediatamente, numa atitude que causa estranheza pois não os lava, apenas seleciona e remove a sujeira aparente. Entrevistado, conta que é vegetariano, formado em biologia, fez mestrado e já trabalhou em Universidade, mas deixou o 
emprego por opção própria, e tem, no momento da gravação, o ofício de vender jornais na rua. Argumenta que ganha pouco e paga aluguel, então recorre às ruas para se alimentar, conhece e seleciona bem o alimento que recolhe, o que the permite manter uma alimentação equilibrada com proteínas e carboidratos, sendo o pão o único alimento que compra. Intrigada, a cineasta o segue depois da xepa da feira e chega a uma sala escondida entre armazéns da estação do metrô, e o encontra dando aulas de francês aos refugiados africanos. O professor escreve numa lousa enquanto os alunos com cadernos estão em mesas anotando; há um entra e sai constante que parece não atrapalhar a aula. Ao conversar com a cineasta, explica que não há pré-requisitos para assistir as aulas, os alunos podem entrar e sair à vontade, ele vai elaborando o conteúdo da aula conforme o grupo que está ali naquele momento, com o objetivo de ensinar a ler e escrever na língua francesa.

Ao final Agnès Varda viaja a Villefranche-sur-Saône, uma cidade a $400 \mathrm{~km}$ a sudeste de Paris, onde está o quadro "Les glaneuses fuyant l'orage"(1857), "As catadoras fugindo da tempestade", de Hédouin (1820-1889). Ela consegue que o quadro seja retirado da reserva e levado ao exterior do museu para ser filmado. Durante a cena bate um vento forte que balança a tela e faz voar os cabelos das funcionárias do museu que o seguram, atualizando a ação registrada no quadro, pois parece uma cena real que estaria acontecendo naquele momento. Ao reafirmar o ato de respigar nas cenas finais do filme, a cineasta reitera sua concepção de arte como fresta iluminadora da realidade, neste filme que aponta uma parte da população normalmente despercebida ou ignorada, pela ação humana invisibilizada.

Trazendo à nossa realidade, pensando na cidade de São Paulo, onde estaria esta população urbana em tempos de isolamento proposto pela pandemia do COVID 19? Sem feiras livres, portanto sem restos; sem trânsito, portanto sem esquinas com faróis de trânsito. As pessoas que puderam se recolheram em casa, as ruas ficaram vazias; a população invisível transbordou nas calçadas, como se tivesse escapado pelas frestas em rompimentos do tecido social, mas não havia quem as olhasse. Ainda veremos ecos deste momento espelhados na arte, refletindo e mediando a experiência do tempo presente. 
O tempo presente se confunde com o ano de 2000, quando o filme foi feito, porém o assunto tratado revela impressionante atualidade, com indicações de permanência num futuro próximo, pós-pandemia, apresentando situações que dependem do esforço humano para uma mudança da sociedade, ainda pouco perceptível nos dias de hoje. É factual, bem real como se espera dos documentários, mas deixa no ar frestas que nos iluminam, tocando na questão essencial da sobrevivência do ser humano, de maneira leve, fluida e profunda.

\section{BIBLIOGRAFIA CITADA}

YAKHNI, Sarah. Cinensaios de Varda: o documentário como escrita para além de si mesmo. Tese (Doutorado em Multimeios), Universidade Estadual de Campinas, Campinas, 2011.

\section{Fontes eletrônicas e sites}

RAMAIN, Paola. 258 Dossier Disponível em: ensigmant.https://www.cnc.fr/cinema/etudes-et-rapports/dossierspedagogiques/glaneurs-les-et-la-glaneuse-dagnes-varda_1036249>. 21 ago 2019. Acesso em 20 ago. 20.

MILLET, Jean-François. Le Glaneuses. Disponível em: https://www.museeorsay.fr/fr/evenements/expositions/aux-musees/presentationgenerale.html?zoom=1\&tx_damzoom_pi1\%5BshowUid\%5D=2110\&cHash=8ac 69a292b. Acesso em 10 set. 20. 